\title{
COMPARISON OF THE OUTCOMES AFTER ENDOSCOPIC VEIN HARVESTING VERSUS OPEN VEIN HARVESTING FOR CORONARY BYPASS SURGERY
}

\author{
Afnan ALMalki ${ }^{1}$ and Ahmed Arifi ${ }^{2}$ \\ ${ }^{1}$ Affiliation not available \\ ${ }^{2}$ National Guard Health Affairs
}

January 5, 2021

\begin{abstract}
Minimally invasive endoscopic vein harvesting (EVH) was first reported in 1996 as an alternative to open vein harvesting (OVH). Making coronary artery bypass surgery a less invasive procedure, shortly after its introduction, it became the standard of care for conduit harvesting. When compared to the conventional technique, the incidence of site infections wound dehiscence, delayed healing, duration of hospitalization, and postoperative pain were markedly reduced. However, the long-term outcomes, safety, and graft patency remain uncertain. Herein is an extensive literature review discussing the outcomes following endoscopic vein harvesting for Coronary Artery Bypass Surgery (CABG) as well as its advantages and disadvantages.
\end{abstract}

\section{Hosted file}

manuscript final for cardiac (1).pdf available at https://authorea.com/users/387586/ articles/502594-comparison-of-the-outcomes-after-endoscopic-vein-harvesting-versusopen-vein-harvesting-for-coronary-bypass-surgery 
Review Article

Title page

COMPARISON OF THE OUTCOMES AFTER ENDOSCOPIC VEIN

HARVESTING VERSUS OPEN VEIN HARVESTING FOR CORONARY BYPASS

SURGERY

-International Review Board approval or waiver: IRB approval is not required. No patients have been investigated in the present paper.

Informed consent: no consent was required 